
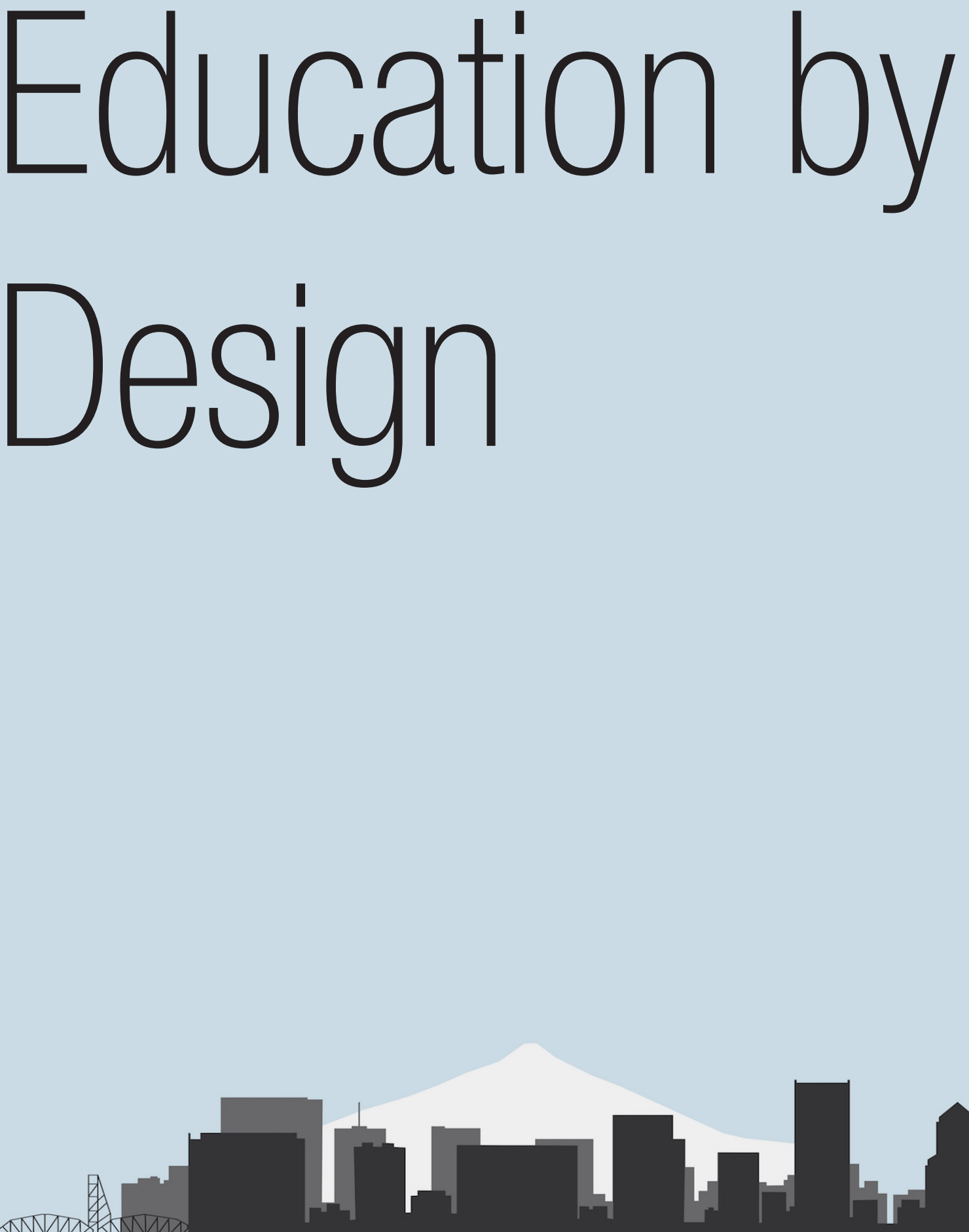

2019 Reynolds Symposium: Education by Design October 18-20, 2019 


\section{Organizing Committee:}

[co-organizers]

Professor Alison Kwok, Ph.D, FAIA, University of Oregon

Emeritus Professor John Reynolds, FAIA, University of Oregon

\section{[Symposium coordinator]}

Isabel Rivera, Ph.D., University of Oregon

Professor Walter Grondzik, P.E., Ball State University

Professor Bruce Haglund, AIA Assoc., University of Idaho

Assistant Professor Emily McGlohn, AIA, Auburn University

Associate Professor Ulrike Passe, lowa State University

Assistant Professor Siobhan Rockcastle, Ph.D., University of Oregon

Sharon Refvem, FAIA, LEED Fellow, Senior Associate and Director, Sustainability Resource Group, Hawley Peterson Snyder 


\title{
Promoting Interdisciplinary Integrated Design Education Through Mass Timber
}

\author{
Judith Sheine \\ Professor \\ University of Oregon \\ Eugene, Oregon \\ jesheine@uoregon.edu
}

\author{
Mark Donofrio \\ Associate Professor \\ University of Oregon \\ Eugene, Oregon \\ donofrio@uoregon.edu
}

\author{
Mikhail Gershfeld \\ Professor of Practice \\ California State Polytechnic University \\ Pomona, California \\ mgershfeld@cpp.edu
}

\begin{abstract}
An integrated design process ideally involves close coordination among the professionals designing architectural, structural, and mechanical systems, and with the construction team and manufacturers of building products; however, this process is not universally followed in practice, nor is it a common model for design education, either in architecture or in engineering. New developments in the United States in mass timber products present a unique opportunity to advance interdisciplinary integrated design processes both in practice and in schools. As architects and engineers explore this field, they are finding that in order to understand material possibilities and limitations and better manage project delivery schedules they need to work in integrated teams from the start, including close coordination with manufacturers, fabricators and construction professionals. Faculty in the University of Oregon (UO)'s Department of Architecture have modelled this integrated practice method in a series of design studios focused on mass timber systems in which student teams either work with architecture faculty and interdisciplinary consultants or with teams of structural engineering students and architecture and engineering faculty. To further this integrated practice model, an interdisciplinary MS degree in mass timber design is being developed by UO's Architecture Department and Oregon State University (OSU)'s Department of Wood Science and Engineering for architecture, structural engineering and construction management students with a professional undergraduate degree. The students will be working on projects in interdisciplinary teams with interdisciplinary faculty teams, preparing the next generation of professionals to be well equipped for a future of integrated design practice.
\end{abstract}

\section{INTRODUCTION}

Ideally, an integrated design process, involving close coordination among design professionals, should be followed in professional practice and in professional design education, but it is far from the norm in either case. However, new developments in engineered wood in the United States that are outpacing their adoption into the design codes are leading professionals increasingly to embrace a performance-based approach to design using alternative means and methods provisions of the codes, which leads to the need for a collaborative design approach. This requires early and intentional coordination between design professionals, construction teams and manufacturers. In the absence of common codified standards that all team members can rely on, the performance-based approach requires the joint development of project goals and standards, in which interdisciplinary conflicts are identified and joint design decisions are made. This level of collaboration is essential, since designers can't just make a decision and assume that other design professionals will be able to effectively resolve their issues within those parameters.

Design education with an emphasis on interdisciplinary teamwork can play an important role in developing future design professionals with integrated design process experience. While this is becoming more common in design education, it is generally a very small part of a much larger number of disciplinary requirements for accredited architecture and engineering programs. While disciplinary competence is a core goal in professional degree programs, this paper will address some methods and models for integrating interdisciplinary courses into design curricula and will describe a fully integrated post-professional degree program. As in professional practice, wood, and mass timber in particular, can serve as an effective material vehicle for this interdisciplinary approach in both architectural and engineering education. While the basics of wood design are commonly included in the U.S. in architecture 
programs and at least half of the U.S. engineering programs include some form of wood design as a required element of the curriculum, mass timber is new to both and can provide a path to demonstrating the benefits of interdisciplinary education for both disciplines.

\section{INTERDISCIPLINARY INTEGRATED DESIGN STUDIOS}

There are a number of models for architecture and structural engineering students and faculty to work together on integrated design projects. In all cases, it is useful to recognize that there are differences in architectural and engineering education approaches. The central focus of architectural education is the design studio, which is a relatively unstructured working environment with an emphasis on artistic vision, experimentation and individual creativity. The more technical content is largely provided through separate lecture courses, and integration and understanding of technology and building systems is often seen as a necessary, but troublesome, aspect of architecture that has to be dealt with to satisfy accreditation and licensing requirements. In structural engineering, the classes include both lectures and labs that focus on science-based problem solving and cooperative teamwork. Quizzes and tests emphasize gaining specific competencies and the focus in undergraduate structural engineering education is on components, rather than on systems. See Figure 1 below.
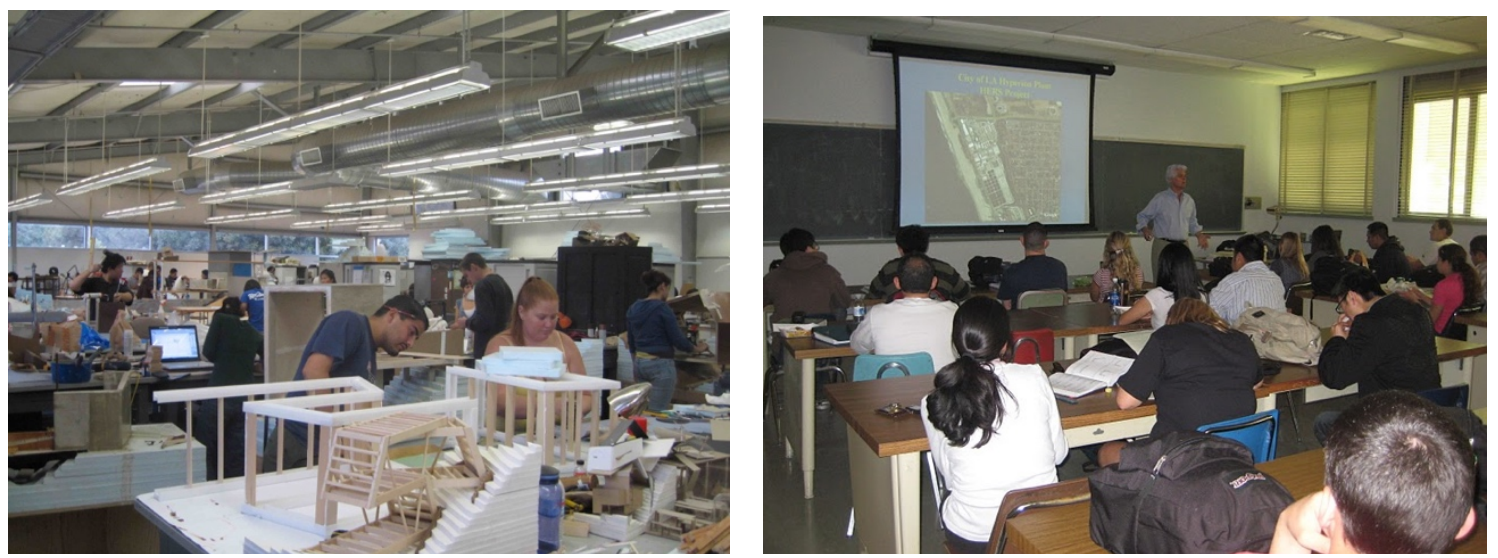

Figure 1. Architecture studio on left, lecture class in Engineering on right.

Architecture students are expected to create new solutions to design problems, although they frequently start with case studies of previous examples of the building types they are addressing in their studios. Engineering students are relatively unfamiliar with the case study method, which is, essentially, a form of reverse engineering in which previous built examples are analyzed for their form, systems and design approach. Public reviews with external professionals are the norm in architecture but are far less common in engineering education. The level of graphic presentation and physical model-making required in architecture is quite high compared to that in engineering classes, while the level of analytics and numerical modeling requiring precision and accuracy that is expected in engineering reports is directly reflected in grading.

The authors have spent over a decade working on various models of integrated studios, with students in the middle or last year of their professional programs (both undergraduate and graduate). While Sheine, a professor in architecture, and Gershfeld, a professor in civil engineering with a specialization in wood design, were both teaching at Cal Poly Pomona (CPP), they taught a series of joint studios with their respective students working in interdisciplinary teams designing timber pedestrian bridges. When Sheine went to the University of Oregon (UO) in 2013, they developed several models for long-distance collaboration, and were joined in 2015 by UO's Donofrio, who has a background in both architecture and engineering. With the development of the TallWood Design Institute (TDI), a collaboration between the UO's College of Design and Oregon State University's (OSU) Colleges of Forestry and Engineering focused on the advancement of timber manufacturing and design through research, testing, outreach and education, an opportunity was provided to develop a fully integrated Master's degree for students with a 
professional degree in architecture, engineering, architectural engineering or construction management, a degree focused on mass timber design with an emphasis on interdisciplinary collaboration.

\section{AE Studios at Cal Poly Pomona}

Our explorations in interdisciplinary education began in 2007 when the Dean of the College of Engineering (CoE) approached Sheine, the Architecture Department Chair, about teaching a joint studio on the design of a timber bridge connecting the two CoE buildings. This project had been approached in several senior capstone projects, but the results, while structurally sound, were not very attractive, leading Gershfeld to propose to the Dean that the project should be a collaboration with the Architecture Department. The choice of timber as the primary material choice was partly dictated by the identification of a potential timber donor, and also by the university sustainability goals and Gershfeld's specialized expertise. Sheine volunteered to work with Gershfeld on this project with the first class offered in winter 2008. Sheine and Gershfeld experimented with several methods and structures for teaching this studio, and by the third one, in 2011, thought a workable model had been developed for the 10-week term.

The CPP studios began with a case study project focused on timber bridges. Students worked in small teams, generally of two, with the architecture students presenting their work after a week, and with the engineering students continuing to study and analyze the structural systems for another week. This oneweek gap allowed the architecture students to develop individual initial concepts - models and drawings - for their bridges and to present them at the beginning of week three. Depending on the size of the classes, similar design concepts were combined, with the goal of having eight to ten projects total, which were subjected to a competitive process, with only four to five projects proceeding past the midterm review. The engineering students were allowed to select the projects, with architecture students having a choice of engineering students for high-demand designs. The combined architecture and engineering student teams (3-4 students on each) worked together on a preliminary design until the mid-term in the sixth week. A series of lectures ran through the first four weeks of the studio, on structural systems for bridges, engineered wood types and properties, and structural connections, given by both the faculty and guest speakers. The mid-term review was conducted by invited external professional architects and engineers who were asked to formally rate the projects, based on structural, aesthetic and constructability criteria. The external ratings provided guidance for which projects would continue, with the faculty making the final determination based on pedagogic goals, almost always allowing one or two very experimental projects to go through if the team appeared to be strongly committed to working it through collaboratively. After the midterm, the teams were further combined so that larger groups of students would be working on the selected designs until the final review in the tenth week, another public review with external reviewers and rankings, and the selection of a "winning" design.

Because the classes were conducted in the architecture design studio, architecture and engineering students worked side-by-side in their teams, with consultation from both Sheine and Gershfeld, largely at the same time. Engineering students quickly grew comfortable working with their architecture colleagues in this messy, noisy space, engaging in energetic dialogue and learning from each other. See Figure 2.
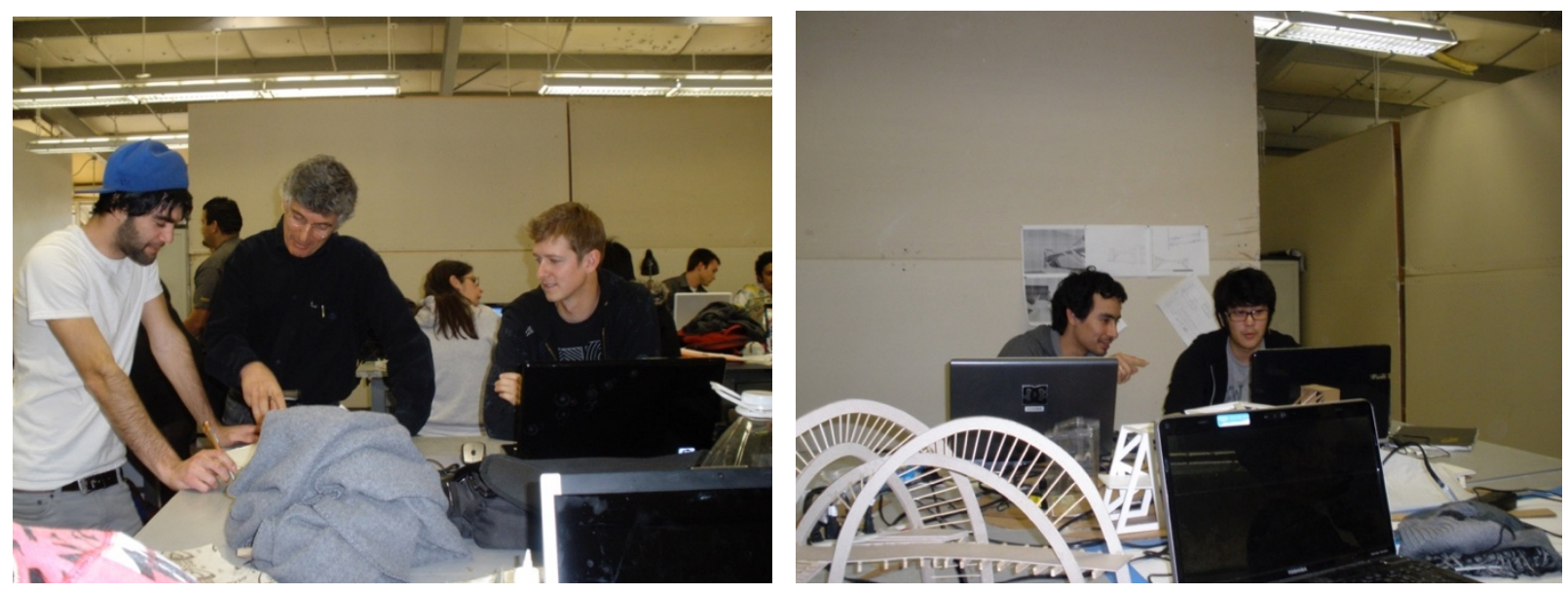
Figure 2. Gershfeld with engineering student Daniel Mourad (left) and architecture student Nathan Houck, (right); engineering student Alex Quinonez (left) and architecture student Eubie Han (right).

The goal was to select a winning project each term, however it was not until the third iteration of the studio in 2010, that the designs seemed sufficiently developed that an actual winner was presented to the Dean of Engineering (due to changing college priorities, the project was not realized). See Figure 3 .
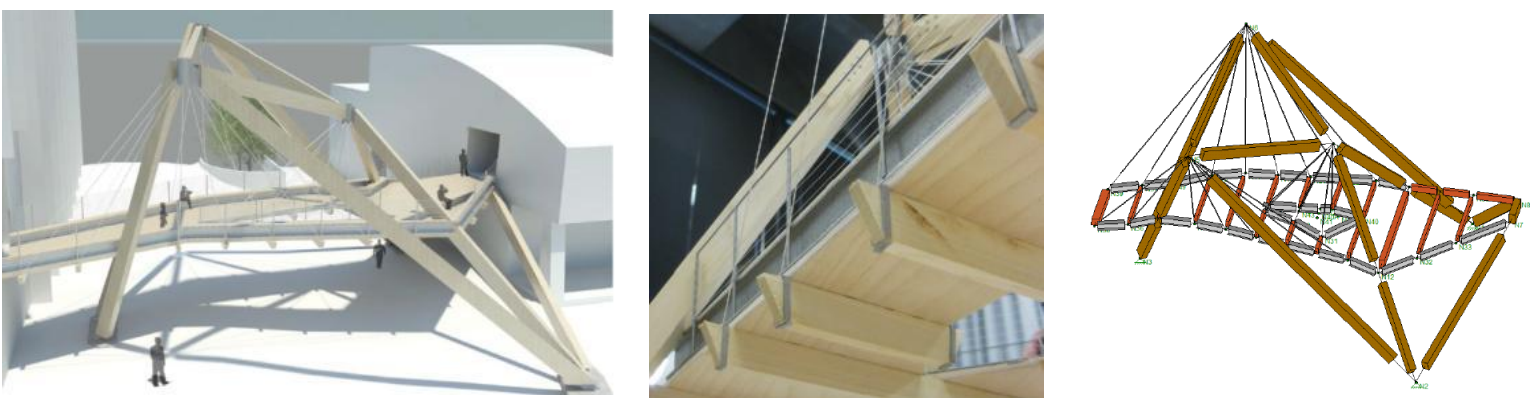

Figure 3. Space Truss Bridge (1st Place), Architecture students: Nathan Houck, Greg Sagherian, Robert Yamnitz, Elane Yiu, Engineering students: Bethany Lopez, Daniel Mourad, Ryan Turner, Samson Wong. Physical models at $1 / 4 "$ and 1" $=1$ '-0",left; digital structural model in RISA 3D, right.

Following this project, the faculty spent two years focused on designing pedestrian bridges in the nearby Los Angeles National Forest, working with a U.S. Forest Service engineer. Although no longer compelled to work in timber, the faculty found a number of pedagogic advantages in doing so. First, Gershfeld had a special expertise in wood design, not common in engineering academics, and the engineering students in the studio were able to take an undergraduate timber design class with him early in their program. Secondly, we found that for the architecture students, if they had worked in steel or concrete, they could plausibly assume that almost any form they came up with could be built (however inefficiently), but timber introduced material form making limitations that required them to work closely with the engineering students on their sometimes very adventurous designs. While the challenge of the architectural designs required the engineering students to explore and design inventive structural systems and connections, far beyond the component level design they had previously experienced, for undergraduates with limited exposure to complex systems, the material limitations allowed control of the complexity of the projects to the level they were able to analyze. In addition, timber presented an opportunity for students to collaborate closely on the design of exposed structural connections, taking into consideration both aesthetic and structural issues. This studio project ran in 2011 and 2012 on two different sites, with the same format as the previous studios. In 2012, the studio produced some particularly sophisticated projects. The 1st place project from 2012 is shown in Figures 4-7.
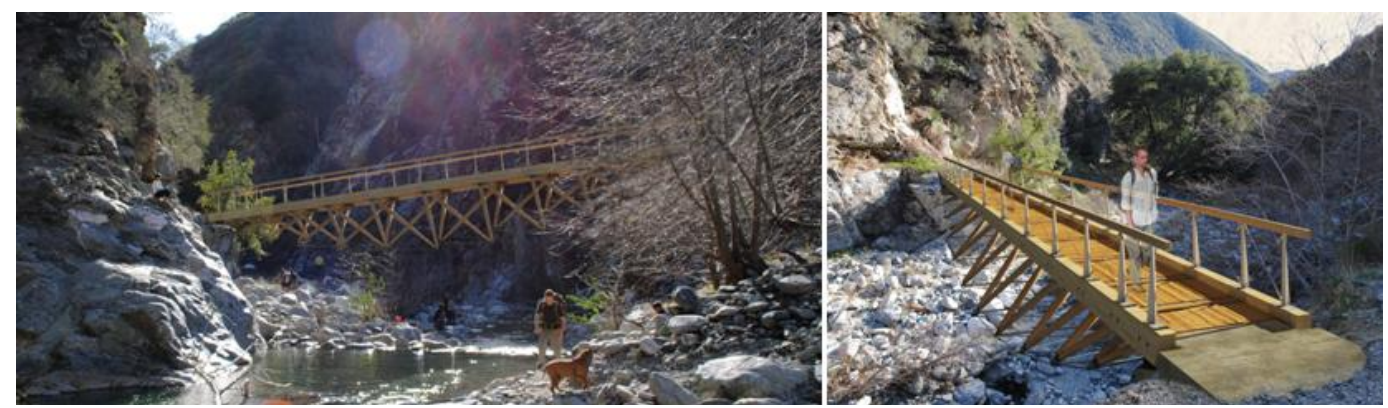

Figure 4. Truss Bridge (1st Place), Architecture students: Richard Delarosa, Candice Myers, Harold Ornelas, Leo Rodriguez, Johnny Tran; Engineering students: Kun Chang, Henry Chi, Huong Vu. 

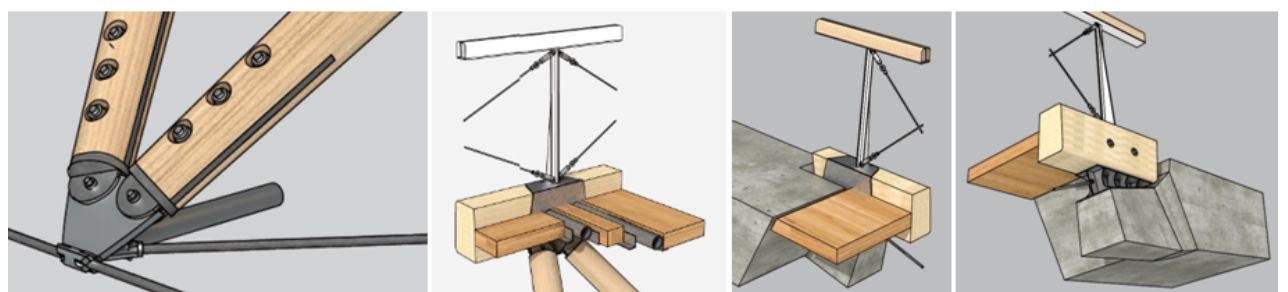

Figure 5. Connection details: truss web bottom and top, support top view and bottom view.
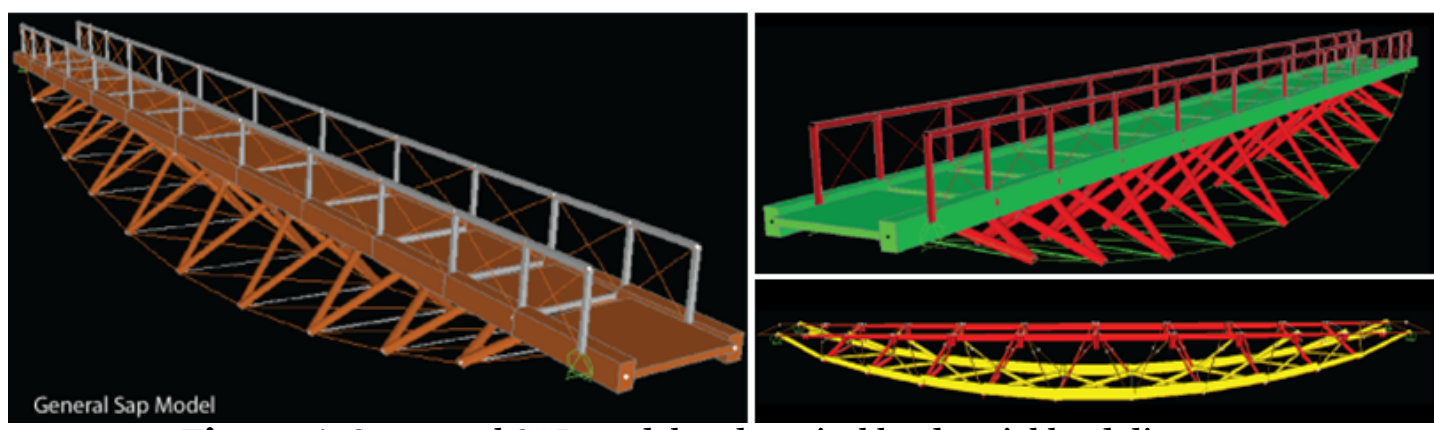

Figure 6. Structural SAP model and vertical loads axial load diagram.
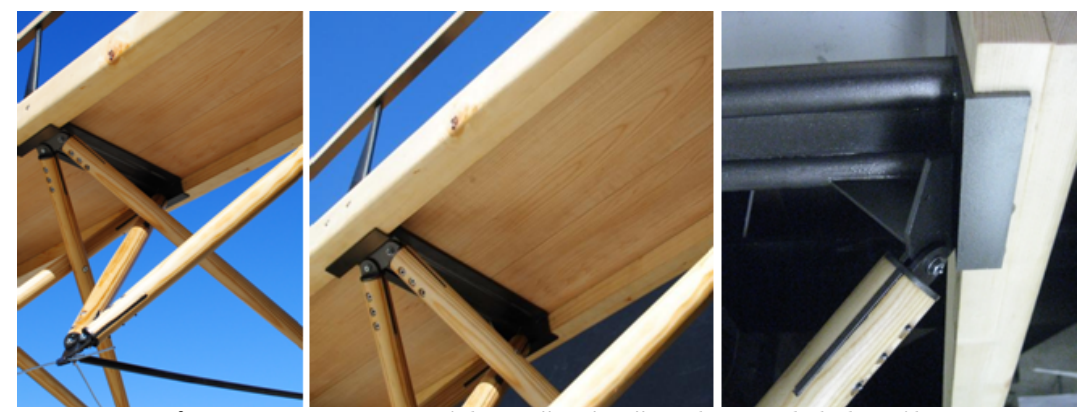

Figure 7. Truss Bridge 3" $=1$ '-o"scale model details

\section{University of Oregon Mass Timber Architecture Studios}

Sheine and Gershfeld tested several interdisciplinary studio models at UO, all focusing on mass timber as the primary structural material. These studios approached projects at a variety of scales and complexity and with varied amounts of collaboration.

In 2013 the UO studio took on the first "Timber in the City" Association of Collegiate Schools of

Architecture (ACSA) competition, focused on mid-rise CLT housing, while Gershfeld worked with a senior project group on a mid-rise mixed-use mass timber building in a high-seismicity area. There was one faceto-face meeting of the student groups, with a joint field trip to wood manufacturing facilities in Oregon, and some web-based video consults for the studio with Gershfeld as technical advisor. Even with this limited interdisciplinary interaction on a large urban project (almost 200,000 sq. ft.), significant technical information was incorporated, with one of the UO teams taking first prize with a proposal for a modular CLT housing project, praised by the competition jury for the quality of its technical development. See Figure 8. 

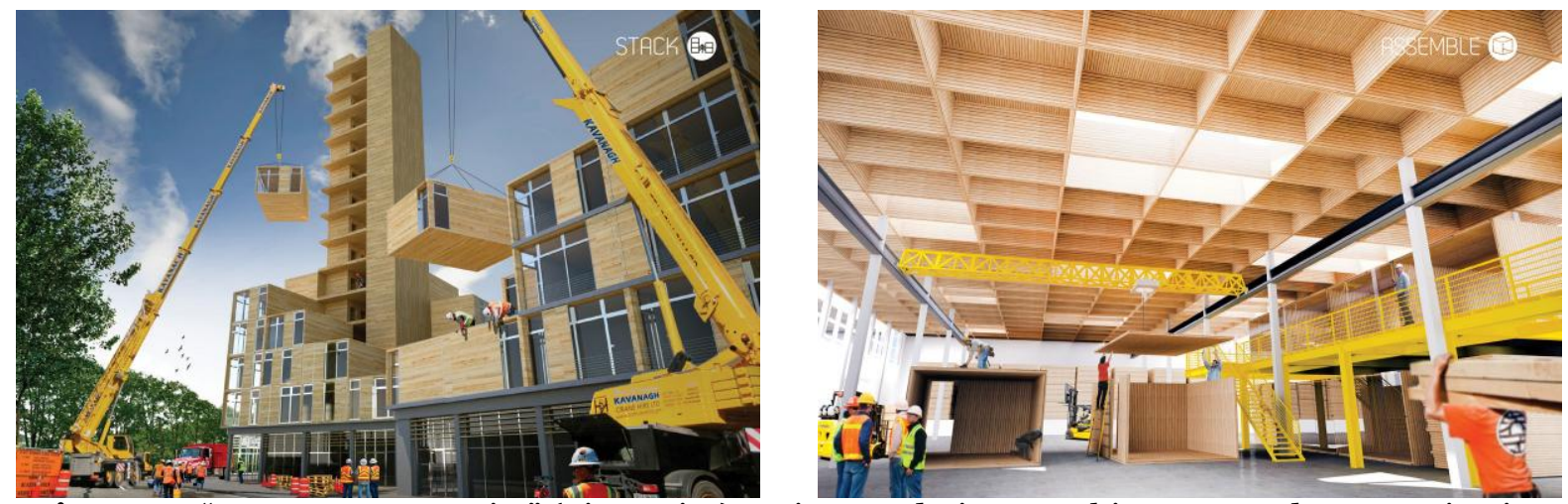

Figure 8. "Grow Your Own City" (First Prize) project renderings. Architecture students: Benjamin Bye, Alexander Kenton, Jason Evan Rood.

In 2016, ACSA ran the "Timber in the City" competition for the second time; this time Sheine co-taught it with Donofrio, with Gershfeld acting as technical consultant; Gershfeld was on sabbatical, so no student interaction was involved, but he was able to come to the studio in person every other week. With this 300,000 sq. ft. project, students working in teams, with input from both Donofrio and Gershfeld, were able to develop a large and complex program on two city blocks, with fairly significant structural development, resulting in one of the UO teams winning second prize. See Figure 9.
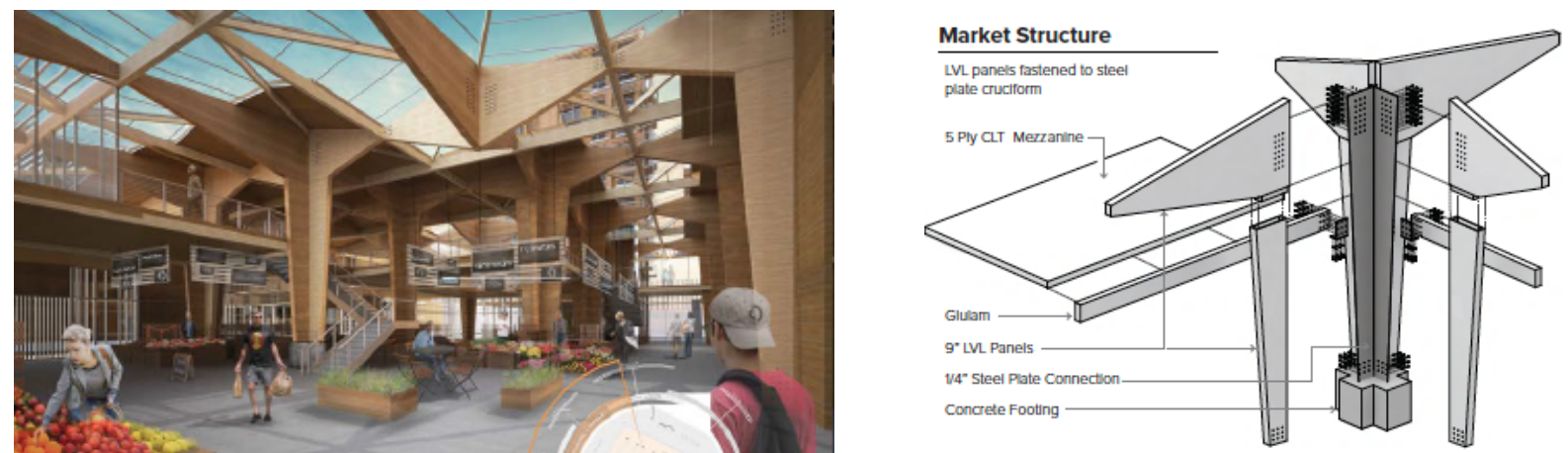

Figure 9. "Hybrid Domains" (Second Prize) project rendering and detail of market hall. Architecture students: Alex Kendle, Michael Meer, Greg Stacy, Ben Wright.

A similar model was followed in a spring 2015 studio, when the city of Springfield, Oregon, asked Sheine to teach a studio on the design of a mass timber parking garage for their new Glenwood development. Given the lack of precedents and the need for structural knowledge of timber systems in a seismic area, Sheine asked UO's Donofrio to co-teach the studio, with Gershfeld, acting as a technical consultant, making several trips to UO as well as giving online consultations. Again, engineering students were not involved in the collaboration. The UO students worked in teams and with the assistance of Donofrio and Gershfeld, made use of new timber lateral-force resisting systems recently developed in New Zealand for the design of the structures. The studio also collaborated with DR Johnson Lumber, in Riddle, OR, which had just begun to produce the first structurally certified cross laminated timber (CLT) panels in the U.S. Nine team designs were produced and demonstrated sufficient structural development to convince the City of Springfield that the project was feasible and to engage architects SRG Partnership and engineers KPFF for the actual project. See Figure 10. 

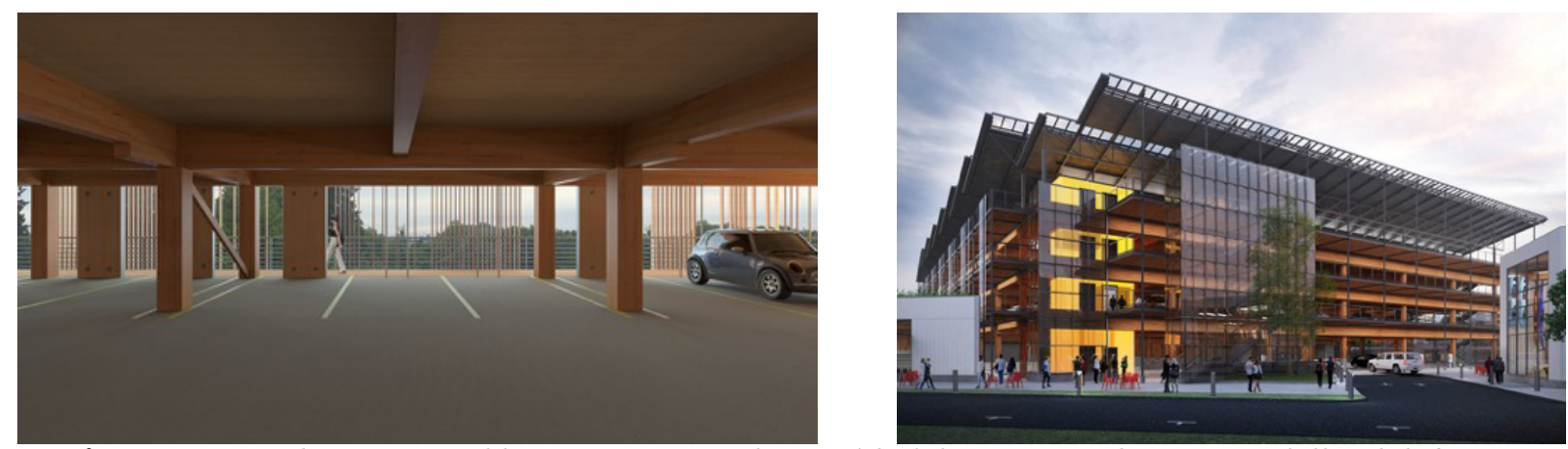

Figure 10. Student proposal by Krysten Gormly, David Lieberman, and Scott McClelland, left; SRG Partnership proposal, right.

Two other studios involved direct, although virtual, collaboration, among architecture and engineering students. In 2014, Sheine and Gershfeld paired individual students in a UO studio with individuals in Gershfeld's CPP graduate level Advanced Timber Design class on a project for a small retreat center in OSU's College of Forestry's McDonald-Dunn Forest. The students communicated remotely, with Gershfeld making several visits to UO. The results were mixed, depending on the individuals involved, and on the complexity of the architectural proposal. Additionally, increasing the number of projects in the studio meant that each had less time with the faculty. Nevertheless, several teams produced elegant and structurally sound projects. The most sophisticated project was the only one designed with a team of two graduate architecture students, who worked with a very strong undergraduate engineering student; the design employed a 48' cantilever with a timber truss system. A second well-developed design was the result of a very effective collaboration between a graduate architecture student and a graduate engineering student who were both very strong. See Figure 11.
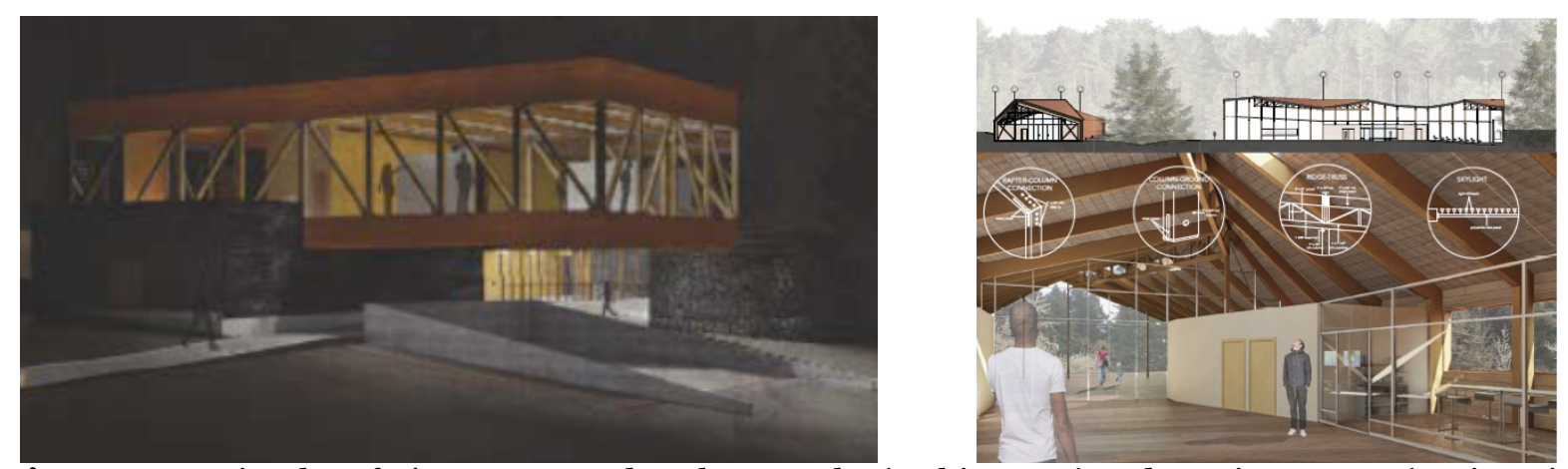

Figure 11. Project by Efrain Vergara and Zach Vacovsky (architecture) and Austin Morgan (engineering), left; project by Kelsey McLaughlin (architecture) and Vicki Rogers (engineering), right.

With the spring 2017 UO studio, Sheine and Gershfeld were able to once again have architecture and graduate engineering student teams collaborate, this time on the design of a new grandstand structure for UO's Hayward Field. This project was closest in type to the bridge projects of the Cal Poly Pomona studios, in which very limited programming or site design was required. Teams communicated virtually, with Gershfeld making several in-person visits to UO. Engineering students were able to do structural analysis and architecture students developed details, as they did for the bridges. See Figure 12. 

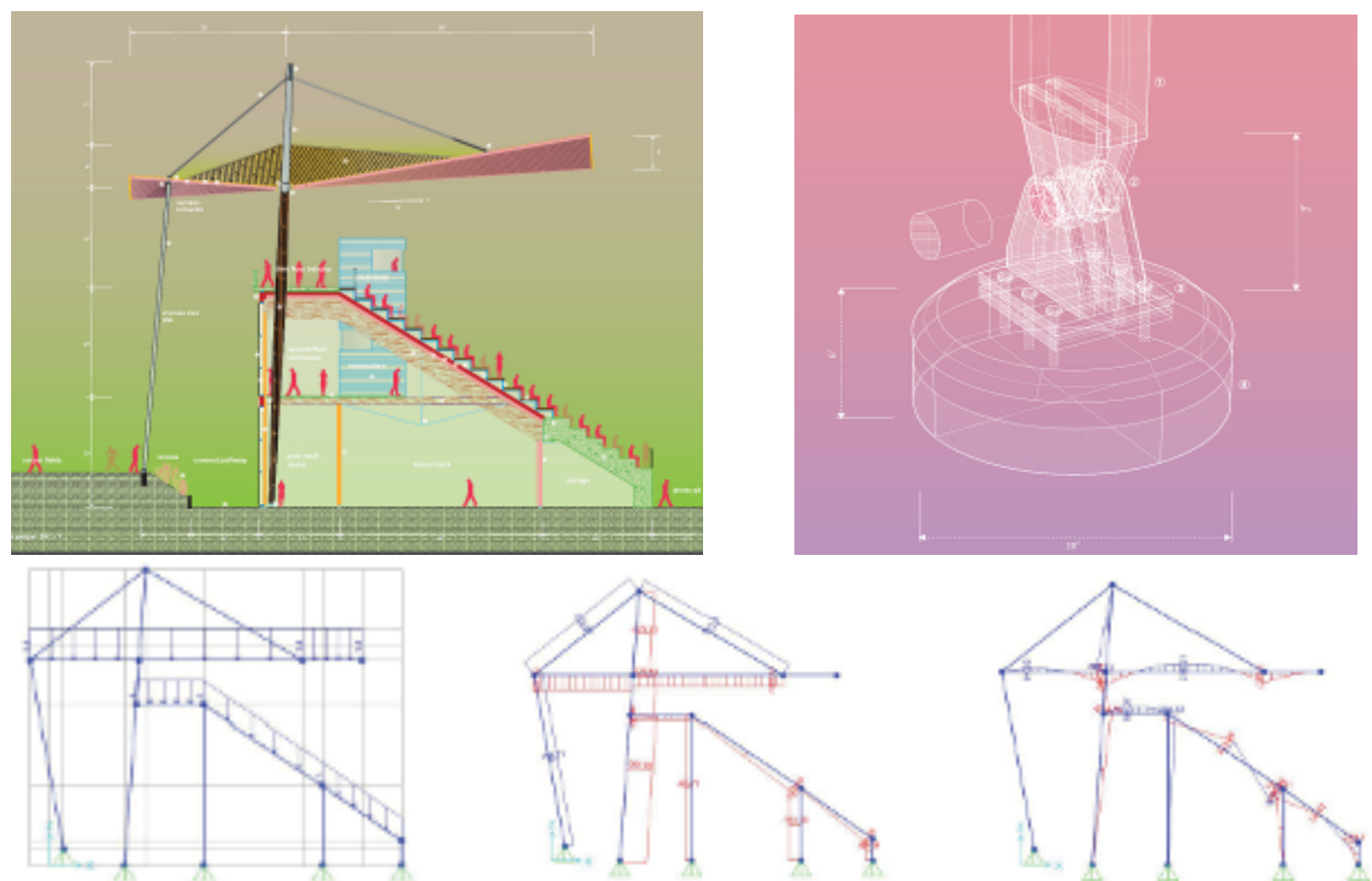

Figure 12. Folded Plate Team: Addison Estrada, Abe Kelso (architecture); Eric Cheung, Gregory Kato, Dana Robertson, Trung Tran (engineering). Section on top, left, detail of column base connection on top, right; Loading, Gravity and Bending diagrams, on bottom, left to right.

Three UO studios taught in 2017-18 focused on buildings of very varied sizes, although all followed a similar format, with Gershfeld acting as technical consultant, and without involvement from engineering students. However, in two of them, the studio included consultants for environmental systems. The fall 2017 studio, co-taught by Sheine and Donofrio, was focused on the design of a new mass timber courthouse for Lane County, a project initiated by the County. This was a 250,000 sq. ft. building with a complex program and students worked in teams of three and four. With generous funding from the County, the studio was able to include faculty consultants from our UO Energy Studies in Building Lab (ESBL) to help integrate natural ventilation and daylighting strategies into the projects. See Figure 13.
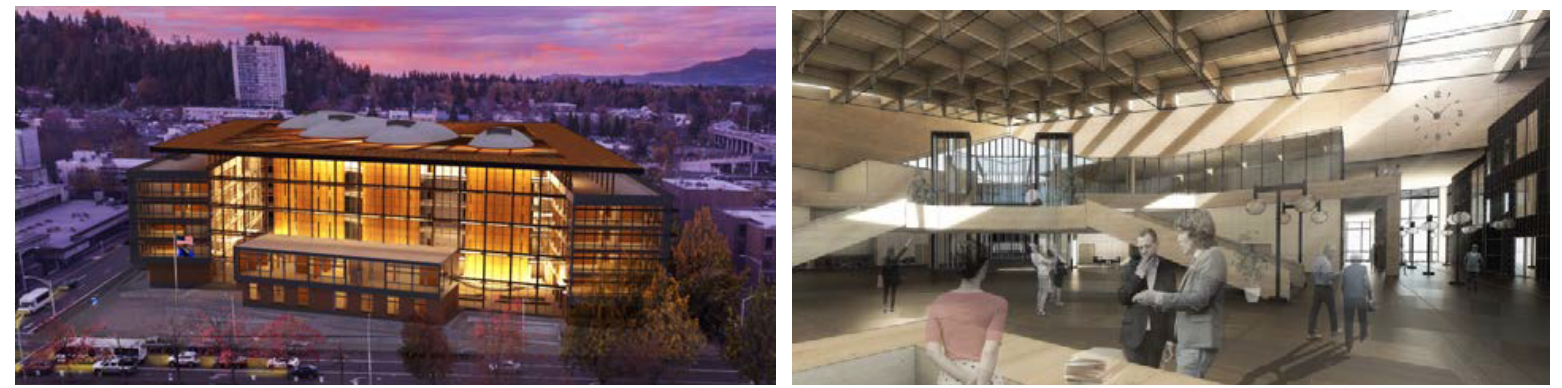

Figure 13. Renderings of proposals by The Nest team (Spencer Boragine, David Moreno, Josh Rosenthal, Zach Sherrod) on left and the Civic Resilience team (Westin Hill, Russell Regulinski, Tim Walsh) on right.

In spring 2018, Sheine's UO studio focused on modular mass timber classroom design, with Gershfeld acting as consultant and with faculty from ESBL consulting on daylight analysis, with the use of the Artificial Sky. Students worked in teams of two, developing mass timber classroom modules, and applied them to existing school plans, designing long-span timber systems for the larger spaces. See Figure 14. 

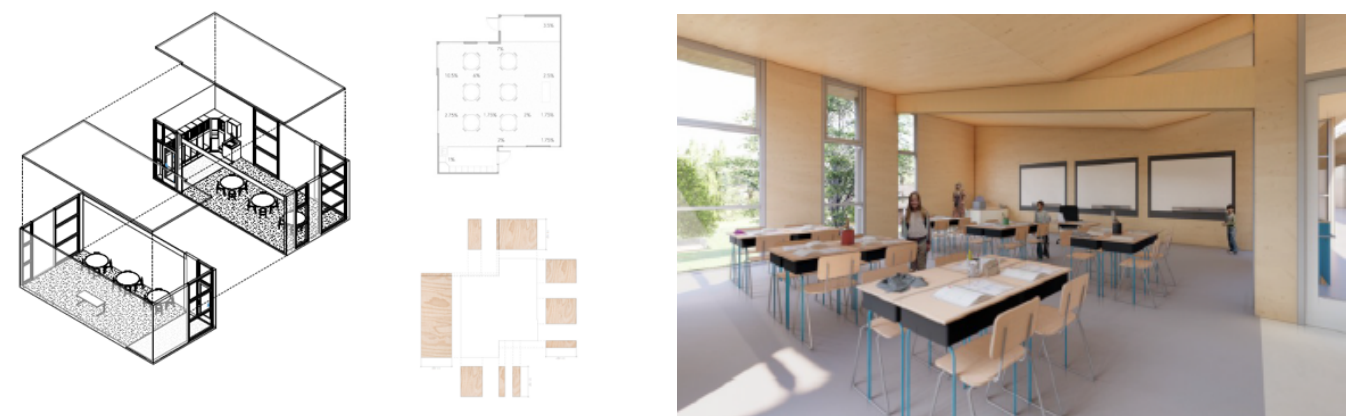

Figure 14. Payton Narancic and Simone O’Halloran. Classroom module for ground floor on left, rendering of upper level classroom on right.

In winter 2018, Sheine taught a studio focused on the design of very small mass timber houses, coordinated with Alex Olsen, an instructor in a construction vocational program for high school students, Freres Lumber, the manufacturer of Mass Plywood Panels (MPP), and with Gershfeld acting as structural consultant. This studio mirrored integrated practice, with a team of architect, engineer, contractor and manufacturer all working together using the new MPP material. Students were able to explore the potential of MPP and develop individual detailed designs in this very small project. See Figure 15.
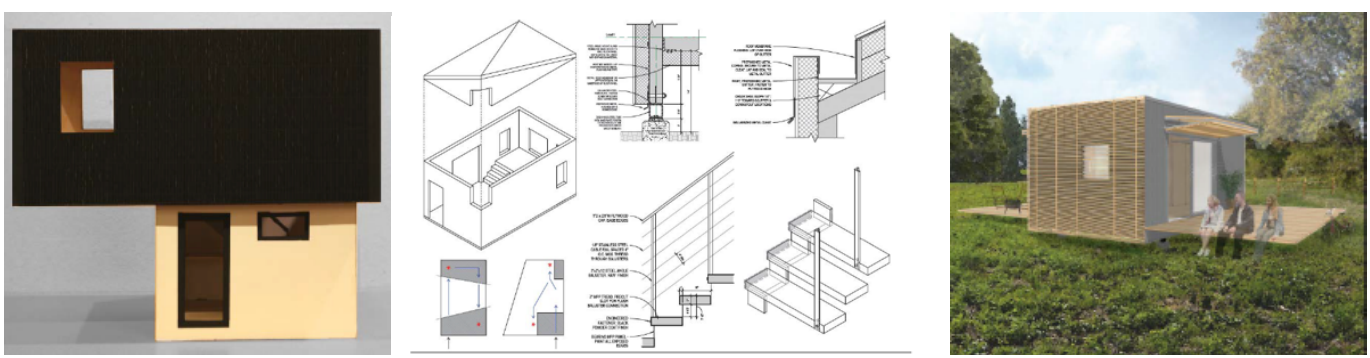

Figure 15. Projects, left to right, by Andrea Li, Hayden Rensch, and Konrad Stuebgen.

\section{LESSONS LEARNED}

Each of these studios and interdisciplinary models taught us something about the various pedagogies and project types. Ideally, interdisciplinary integration should be in person, but, as in practice, virtual communication can work, although it's best if the number of projects is limited and close faculty supervision is available, which is challenging in a lecture-style engineering class. One note is that all of these studios were taught in 10-week terms, which makes them particularly challenging. From the studio types discussed here, three primary models can be derived. These models generally have distinct advantages when students work in teams, either in interdisciplinary teams or even just in teams of architecture students. Clearly, there is an advantage in having a number of students able to produce more work than one can, but there is also a benefit to having students work in teams and finding different ways each can contribute to support the team and project - as is typical in practice. Additionally, less experienced students can work with stronger ones, giving opportunities for both leadership and peer-topeer learning. And, critically, the importance of having faculty leading these efforts who have experience in hands-on design and can demonstrate productive collaborative interaction cannot be overestimated.

\section{Structurally-driven projects}

Projects that have very limited program, such as bridges, grandstands, and parking garages, are best suited to a 10-week fully integrated design process with architecture and engineering students working together from the beginning of a project. These projects can create interesting new challenges for both architecture and engineering students; architecture students rarely address designs that require serious structural analysis to establish feasibility and engineering students rarely tackle in-class analysis and design of an entire structural system that is not a simple box. The progressive competition format has advantages in establishing high standards in both design and collaboration that must be met in order for a design to proceed to a further stage of development and in having students work in teams where they 
learn how to make contributions even when they are not the primary author of the design idea. Considerable development and a relatively high level of resolution can be achieved with these kinds of projects, with or without the progressive competition model.

\section{Buildings}

Depending on the size of the building program, these are generally much more architecturally driven at the beginning of the design project. Architecture students take the lead on site design and conceptual design, which in a large, complex building can take some weeks. The challenge in these cases is how to integrate technical team members early enough to be involved in the entire design process. This applies to both structural engineering students and to the integration of environmental systems, whether this input is provided by consulting faculty and professionals or also by students. In these projects, case studies can form a critical part of the teamwork. Engineering students can analyze past examples of structural systems and present alternates to the architecture students as they develop conceptual designs. Similarly, standards and systems for analysis of ventilation, cooling, heating and daylighting strategies can be investigated and presented for consideration. In general, projects that have some standard, repetitive parts - offices, residences, schools - combined with one or two long-span spaces give both architects and engineers a good variety of types of spaces to design and learn from, one lending itself to a fairly standard solution and one allowing for more creative exploration. Lectures from faculty as well as external design, construction and manufacturing professionals, along with field trips, can provide supplemental knowledge for students and give them direct insight and understanding of projects.

However, with more complex projects, early integration of technical team members can be particularly challenging, especially in a 10-week term. These projects, such as the "Timber in the City" competitions, are architecturally driven and are better suited to technical integration provided by faculty and professional consultants. Of course, on a small project, a single residence or similar size structure, it is possible to have individual students work on projects, as is also typical in practice. Finding a building of just the right size and complexity for successful teamwork and interdisciplinary collaboration is part of the challenge for faculty instructors.

\section{INTERDISCIPLINARY MASTER'S DEGREE PROGRAM}

From the launch of the TallWood Design Institute (TDI) in 2015, an interdisciplinary MS degree was envisioned focused on mass timber design, taking advantage of Oregon's position as the epicenter of mass timber manufacture and application in the U.S., the role of TDI in this development, and the disciplinary strengths of UO and OSU faculty in architecture, wood science and engineering. While the goal is to eventually offer the MS as a joint degree from both universities (addressing the logistical challenges of creating a joint degree from two public universities will take some time and effort to accomplish), we are planning to initiate it in fall 2020 as a one-year UO Department of Architecture Master of Science degree, with classes taught at both universities. The program is designed for students with a professional degree in architecture, structural engineering, architectural engineering, construction management or other allied fields.

Based on the experiences described above, Sheine, Gershfeld and Donofrio worked with Eric Hansen, Professor and Head of the OSU Department of Wood Science and Engineering (WSE), to develop the MS program. All students will be required to take all courses. The fall term will include three courses introducing students to forestry, wood markets, wood science, wood manufacturing and structural wood design; these will be taught by OSU WSE faculty at OSU. A fourth course, a studio focused on wood design with digital tools, will be taught at UO with faculty from Architecture and WSE. In the winter students will be offered an option to travel to Europe for the annual Holzbau in Innsbruck, Austria and a tour of significant timber structures and wood manufacturing facilities.

The winter and spring terms will be centered on a capstone studio project, in which students will work in interdisciplinary teams on the design of a building with repetitive elements and a long-span space. As indicated above, the architecture students will begin with brief case-study projects, while the engineering and construction students will spend more time on case study analysis for the first four weeks. This will 
give the architecture students time for site planning and conceptual design while interacting with their technical team members, who will be providing feedback on the design approaches. After this initial phase, the team members will work together to develop the project, with each team member taking major responsibility for the aspects of the project that correspond with their discipline. This studio will be jointly led by an architecture faculty member and an engineering faculty member, with guest consultants.

In the winter term, a lecture course will be taught by the lead studio faculty, covering aspects of timber design relevant to all disciplines. There will also be a two-term seminar, sponsored by TDI, with guest lectures and workshops given by UO and OSU faculty with specialized expertise and by external professionals. Topics will include: manufacturing processes, digital fabrication, adhesives, fire resistance, durability/moisture protection, LCA, net-zero design/carbon negative design, acoustics, constructability and economics, construction methods/design-build, modular and off-site construction, and case studies of contemporary mass timber buildings. These guests will also serve as consultants in the studio, advising on their particular areas of expertise. In addition, small interdisciplinary teams will be required to take on a research project of their choice, working with UO and OSU faculty members.

This degree path is designed to prepare students with a professional degree specifically for integrated mass timber practice. However, given that timber buildings require the use of concrete and steel and there are a number of models for hybrid structural models, we believe this degree will prepare students for integrated practice in general.

\section{CONCLUSION}

There are many models for interdisciplinary design education. While virtual interaction is second to inperson collaboration, the reality of current practice - and education - sometimes necessitates communication at a distance and it can be made to work. The authors are looking forward to expanding the scope of their previous interdisciplinary integrated studios to a year-long program with multiple courses and multiple faculty and visitors, both in-person and communicating virtually, and to continuing to refine and develop the degree and the integrated design process.

\section{REFERENCES}

Cramer, Steven and Dan Wheat, 2011. “Education in Wood Structural Design: Who Needs It?” In: STRUCTURE Magazine, June 2011: 5.

Donofrio, Mark, Judith Sheine, and Mikhail Gershfeld. 2016. "The R\&D (Research and Design) Studio: A Model for Integrated Design Studios Fostering Material Innovation.” In: World Conference on Timber Engineering Proceedings, 2016.

Gupta, Rakesh, and Vijaya Gopu. 2005. "Wood Engineering Education - Trends and Challenges.” In: Proceedings of the Structures Congress, 2005.

Gershfeld, Mikhail, Judith Sheine, and Gary McGavin. 2011. "AE Studio - Beyond Pedestrian Access: Creating Bridges for Learning.” In: ASEE Annual Conference Proceedings, 2011.

Gershfeld, Mikhail, and Judith Sheine. 2013. "Design of Timber Bridges in an AE Studio." In: Proceedings of the International Timber Bridge Conference, 2013.

Riggio, Mariapaola, Nancy Cheng. 2019. “Timber tectonics in the digital age: interdisciplinary learning for data-driven wood architecture." In: Proceedings of the ICSA 2019 International Conference on Structures and Architecture. July 24-26, 2019, Lisbon, Portugal.

Riggio, Mariapaola, Jan Helge Siem, Judith Sheine, Laurence Schimleck, Bjorn Otto Braaten, and Arnstein Olav Gilberg. 2016. "What Can Architecture Students Learn About Wood and Wood Science and Engineering Students Learn About Architecture.' In: World Conference on Timber Engineering Proceedings, 2016. 
Sheine, Judith, and Mikhail Gershfeld. 2014. "Case Study: Models for Architecture and Engineering Collaboration in Higher Education Using Mass Timber, a Modern Sustainable Material.” In: Sustainable Structures Symposium Proceedings, 2014.

Sheine, Judith, and Mikhail Gershfeld. 2018. "Hayward Field Mass Timber Grandstands: Promoting Innovative Design Through Interdisciplinary Education.” In: World Conference on Timber Engineering Proceedings, 2018. 